\title{
Primary care management of otitis media among Australian children
}

\author{
Hasantha Gunasekera, Tony E O'Connor, Shyan Vijayasekaran and Christopher B Del Mar
}

O titis media has been prevalent among children throughout history. Australian Aboriginal children experience otitis media from a younger age, ${ }^{1}$ more frequently, for longer periods and with more complications than other children around the world. ${ }^{2}$ Otitis media is also a major cause of morbidity among non-Indigenous children: it affects nearly every child at least once, ${ }^{3}$ and is one of the most common causes of health care presentations, ${ }^{3}$ antibiotic prescriptions, ${ }^{4}$ and hearing impairment in children. ${ }^{5}$

Acute otitis media (AOM) is one of the most common reasons for severe pain in infants and children. Nearly everyone is affected in childhood, usually by 1 year of age. AOM is an inflammatory process in the middle ear, often following a day or two after an acute respiratory infection. Pain is thought to be due to obstruction of the eustachian tube and consequent changes in pressure that stimulate stretch receptors in the tympanic membrane. Infants poorly localise the pain, so it is standard clinical practice to examine the tympanic membranes of all febrile and distressed infants in primary care. However, it can be hard to visualise the membranes in unhappy infants, and diagnosis is often difficult.

Another consequence of AOM is persistent middle ear effusion causing conductive hearing impairment. ${ }^{6}$ This hearing loss is often not appreciated by parents, carers and clinicians, and may result in speech, language, and learning delays and behaviour problems.

\section{Management of acute otitis media}

Box 1 provides a summary of treatment options for AOM among Indigenous and non-Indigenous patients.

\section{Antibiotic therapy}

The microbiological pathophysiology of AOM suggests that antibiotic therapy should be effective by treating any bacteria underlying the inflammation. However, middle ear inflammation is not always accompanied by bacterial infection. Often, only viruses, and no potential pathogens, are found. ${ }^{10}$ Randomised trials comparing antibiotic therapy with controls yield very disappointing results. In most cases, antibiotic therapy makes no difference to the resolution of the pain within 24 hours, and over the following few days, most (15 out of 16 patients) gain no reduction of pain. ${ }^{11}$ Antibiotic therapy makes no difference to persistent conductive hearing loss caused by middle ear effusion. Its marginal benefits are offset by the common (although usually mild) adverse effects of antibiotics, such as diarrhoea, rashes and abdominal pain (in one in 24). ${ }^{11}$

A search for subgroups of children who might benefit from antibiotics using meta-analysis of individual patients (rather than of the different trials) found that antibiotic therapy was more likely to be successful among children under 2 years of age with bilateral otitis media and those with discharging ears. ${ }^{11}$ However, $85 \%$ of cases of AOM resolve within a week with no treatment (Box 2). Indigenous Australian children are an exception: the Office for Aboriginal and Torres Strait Islander Health national guidelines

\section{ABSTRACT}

- Acute otitis media (AOM) is diagnosed on the basis of acute onset of pain and fever; a red, bulging tympanic membrane; and middle ear effusion.

- AOM is managed with analgesia (paracetamol or nonsteroidal anti-inflammatory drugs). Antibiotic therapy is minimally effective for most patients; it is most effective for children $<2$ years with bilateral otitis media and for children with discharging ears. National guidelines recommend antibiotic therapy for Indigenous children with AOM. Evidence for corticosteroids, topical analgesia and xylitol are scant.

- Otitis media with effusion (OME) is diagnosed as the presence of middle ear effusion (type B tympanogram or immobile tympanic membrane on pneumatic otoscopy) without AOM criteria.

- Well children with OME with no speech and language delays can be observed for the first 3 months; perform audiological evaluation and refer to an ear, nose and throat (ENT) specialist if they have bilateral hearing impairment $>30 \mathrm{~dB}$ or persistent effusion. Children with effusions persisting longer than 3 months can benefit from a 2-4-week course of amoxycillin.

- Chronic suppurative otitis media is a chronic discharge through a tympanic membrane perforation. It is managed with regular ear cleaning (dry mopping or povidone-iodine [Betadine] washouts) until discharge resolves; topical ear drops (eg, ciprofloxacin); audiological evaluation; and ENT review.

MJA 2009; 191: S55-S59

recommend treatment of all Indigenous children with AOM with antibiotics at the initial visit. ${ }^{7}$

The unimpressive benefits of antibiotic therapy, combined with increasing anxiety about antibiotic resistance in the community, have led to decreasing antibiotic prescribing among many general practitioners. ${ }^{13}$ But there is now a void in the options for the management of AOM.

\section{Non-steroidal anti-inflammatory drugs}

Addressing the pain with analgesic anti-inflammatory drugs makes sense clinically. However, there is limited evidence for their use for AOM specifically. Effectiveness is likely to be generalisable from evidence for treatment of the less acutely painful condition of nonspecific common cold. ${ }^{14}$ There is surprisingly little evidence to support the use of paracetamol to reduce fever or pain in AOM, but some evidence that it has an analgesic effect in other conditions. ${ }^{15}$

\section{Corticosteroids}

Steroids are used in many medical settings to reduce inflammation, although there is concern about their use in life-threatening 


\begin{tabular}{|c|c|c|c|c|}
\hline \multicolumn{2}{|c|}{$\begin{array}{l}1 \text { Guidelines for the initial management of ac } \\
\text { should also be provided } \\
\text { Child with AOM }\end{array}$} & \multicolumn{3}{|c|}{ Guideline recommendations } \\
\hline Age & Presentation & $\begin{array}{l}\text { OATSIH guidelines }{ }^{7} \text { for } \\
\text { Indigenous children }\end{array}$ & $\begin{array}{l}\text { Australian therapeutic } \\
\text { guidelines }\end{array}$ & $\begin{array}{l}\text { American Academy of } \\
\text { Pediatrics guidelines }\end{array}$ \\
\hline$<6 m$ & $\begin{array}{l}\text { AOM without perforation } \\
\text { AOM with perforation }\end{array}$ & $\begin{array}{c}\text { Amoxycillin, } \\
50 \mathrm{mg} / \mathrm{kg} / \text { day for } 7 \text { days } \\
\text { Amoxycillin, } \\
50-90 \mathrm{mg} / \mathrm{kg} / \text { day for } 14 \text { days }\end{array}$ & $\begin{array}{l}\text { Amoxycillin, } \\
45 \mathrm{mg} / \mathrm{kg} / \text { day for } 5 \text { days }\end{array}$ & $\begin{array}{c}\text { Amoxycillin, } \\
80-90 \mathrm{mg} / \mathrm{kg} / \text { day for } 10 \text { days }\end{array}$ \\
\hline $6 m-2 y$ & $\begin{array}{l}\text { Diagnosis uncertain; mild symptoms* } \\
\text { Severe symptoms }{ }^{\dagger}\end{array}$ & $\begin{array}{c}\text { Amoxycillin, } \\
50 \mathrm{mg} / \mathrm{kg} / \text { day for } 7 \text { days }\end{array}$ & $\begin{array}{c}\text { Observe } 1 \text { day } \\
\text { Amoxycillin, } \\
45 \mathrm{mg} / \mathrm{kg} / \text { day for } 5 \text { days }\end{array}$ & $\begin{array}{c}\text { Observe } 2 \text { days } \\
\text { Amoxycillin, } \\
\text { 80-90mg/kg/day for } 10 \text { days }\end{array}$ \\
\hline$>2 y$ & $\begin{array}{l}\text { Diagnosis uncertain or mild symptoms* } \\
\text { Severe symptoms }{ }^{\dagger}\end{array}$ & $\begin{array}{c}\text { Amoxycillin, } \\
50 \mathrm{mg} / \mathrm{kg} / \text { day for } 7 \text { days }\end{array}$ & $\begin{array}{c}\text { Observe } 2 \text { days } \\
\text { Amoxycillin, } \\
45 \mathrm{mg} / \mathrm{kg} / \text { day for } 5 \text { days }\end{array}$ & $\begin{array}{c}\text { Observe } 2 \text { days } \\
\text { Amoxycillin, } \\
80-90 \mathrm{mg} / \mathrm{kg} / \text { day for } 10 \text { days }\end{array}$ \\
\hline
\end{tabular}

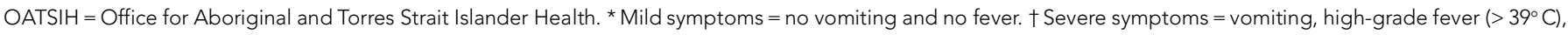
severe pain, perforation and bilateral disease.

infections due to their immunosuppressive effects. Although there is some evidence suggesting that corticosteroids are effective for treating several acute respiratory infections, ${ }^{16,17}$ there is limited evidence to support their use for otitis media. ${ }^{18}$

\section{Topical analgesics}

A traditional home remedy for the pain of AOM is warmed olive oil introduced into the external ear canal to soothe the painful ear drum. Several proprietary preparations are used for this (more commonly in the United States than Australia), but the evidence for this treatment is too scant to be sure that it is effective. ${ }^{19}$

\section{Xylitol}

Xylitol is a low-kilojoule sugar alternative with antibacterial activity used in some chewing gums to reduce dental caries. ${ }^{20}$ It has been trialled as a preventive for AOM (with the thinking that the chewing action and xylitol would both help) and shown to be effective. ${ }^{21}$ However, evidence from more studies will be required before this can become standard practice, and chewing gum is not possible for young infants.

\section{Tympanostomy tubes}

Tympanostomy tubes (also known as ventilation tubes or "grommets") are recommended for the treatment of recurrent $\mathrm{AOM}^{22}$ Tympanostomy tube placement for $\mathrm{AOM}$ reduces recurrence rates in comparison to a course of antibiotic therapy. However, consensus has not been achieved regarding the number of episodes that constitutes clinically significant recurrent AOM. The current recommendation for tympanostomy tube placement is three or more separate episodes of AOM in 6 months, or four or more episodes in 12 months. $^{23}$

\section{Management of otitis media with effusion (glue ear)}

Most new middle ear effusions clear spontaneously within 3 months, and there is no evidence to support the immediate use of antibiotic therapy following a new diagnosis of otitis media with effusion (OME). ${ }^{24}$ For these reasons, the Australian Therapeutic guidelines: antibiotic ${ }^{8}$ and American Academy of Pediatrics guidelines $^{25}$ recommend observation for children with OME who do not have other risk factors, such as speech and language delays (Box 3). There is no evidence of sustained benefit from oral or topical steroids. ${ }^{26}$ Similarly, decongestants and antihistamines are of no benefit, can cause gastrointestinal or central nervous system side effects, and are not recommended. It is therefore not surprising that screening for OME has not been shown to provide any tangible benefits in the developed world. ${ }^{27}$

For children with effusions persisting for 3 months, the rate of spontaneous resolution is only about $20 \%$ over the next 3 months. In this situation, long-term oral antibiotics (2-4 weeks) may have a modest benefit. ${ }^{28,29}$ An alternative therapy with low cost, low risk of harm and with potential benefit is auto-inflation. This is essentially any action that reproduces a Valsalva manoeuvre, such as forced exhalation with closed mouth and nose, or blowing up a balloon

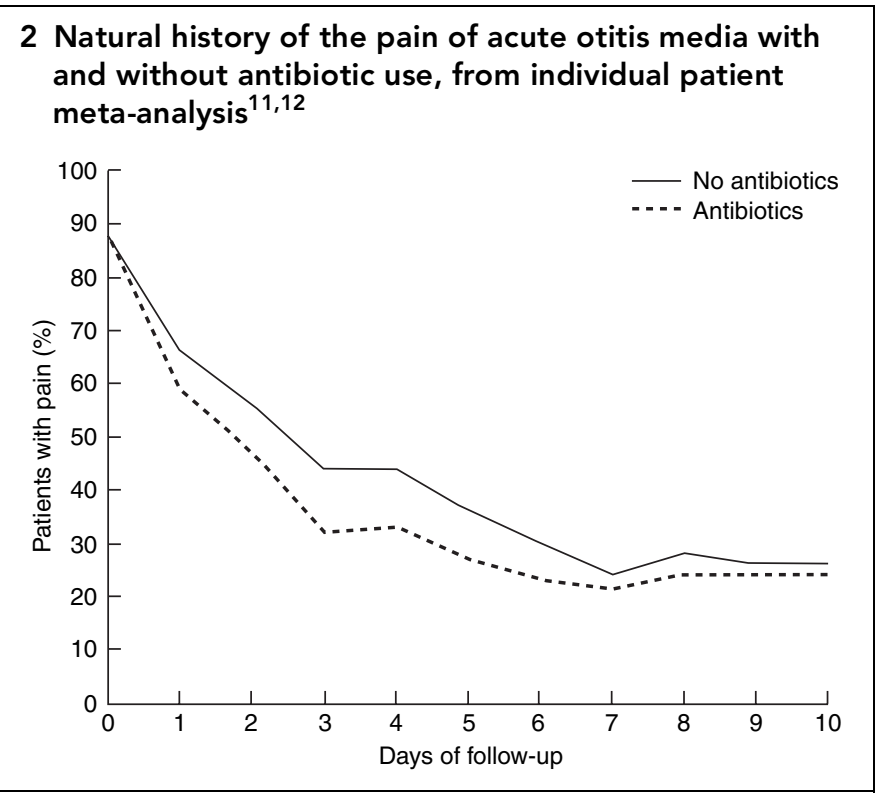


through each nostril, to force air into the middle ear through the eustachian tube. Some trials showed impressive results, but the trials were too small to be certain of a consistent effect. ${ }^{30}$

Audiological evaluation is important to help guide further management. Children with middle ear effusions persisting longer than 3 months, those with effusions associated with bilateral hearing impairment greater than $30 \mathrm{~dB}$ on audiometry, and those with significant retraction pockets in the tympanic membranes should be referred to an ear, nose and throat specialist for consideration of tympanostomy tubes, and possible adenoidectomy in recurrent cases.

Tympanostomy tubes reduce the mean time with effusion by $32 \%$ over the next year and improve hearing, particularly during the first 6 months after surgery. ${ }^{31}$ Despite these clear short-term benefits, the long-term effects of tympanostomy tubes in otherwise well children with mild hearing impairments $(<30 \mathrm{~dB})$ on speech, language, cognition and school performance are disappointing. ${ }^{32}$ However, these data were obtained from the developed world, where populations have lower otitis media burdens than do disadvantaged populations, such as Australian Aboriginal children; this makes generalisation to the Indigenous Australian setting problematic.

The critical period for tympanostomy tubes is when children are young, before school entry and when language skills are being developed. Recurrent and prolonged otitis media may result in poorer receptive and expressive language skills, ${ }^{6}$ and surgical intervention may improve these children's quality of life. ${ }^{33,34}$ The benefits need to be balanced against the risks, which include the risks associated with anaesthesia, ${ }^{25}$ tympanosclerosis, and persistent perforation with or without otorrhoea. Chronic perforations occur in $2 \%$ of children after short-term tympanostomy tubes and in up to $17 \%$ of children with long-term tubes. ${ }^{25}$ Tympanostomy tubes are a common cause of chronic ear discharge.

In addition to tympanostomy tubes and the other management options described above, the parents, carers and teachers of children with OME must be made aware of the likely hearing impairment and the potential impact on behaviour. This can be ameliorated by preferential seating, non-verbal cues, and reduced background noise. ${ }^{25}$ Amplification devices are an option for children with severe and prolonged hearing impairment. These devices can be obtained from Australian Hearing following review by an otolaryngologist.

\section{Management of chronic suppurative otitis media}

Chronic suppurative otitis media should be treated with ear cleaning ("ear toilet") and topical antibiotics. ${ }^{35}$ Ear cleaning can be achieved using tissue spears (dry mopping) or with povidoneiodine (Betadine) washouts. Ciprofloxacin drops are listed on the Pharmaceutical Benefits Scheme for Aboriginal and Torres Strait Islander children with chronic suppurative otitis media, but are not currently listed for non-Indigenous children. Ciprofloxacin drops have an advantage over dexamethasone-framycetin-gramicidin (Sofradex) drops as they are not ototoxic. If it is not clear whether the discharge is acute or chronic, the best option is to treat as for AOM with perforation - ear cleaning, topical antibiotic therapy and 14 days of oral amoxycillin. If the discharge has been present for over 2 weeks, the evidence for oral antibiotic therapy is weak. Trimethoprim-sulfamethoxazole has been shown to increase resolution rates in the short term, but by 6 weeks there was no difference between those treated with topical therapy plus oral antibiotics compared with topical therapy alone. ${ }^{36}$

\section{Vaccination}

Streptococcus pneumoniae and Haemophilus influenzae are two of the commonest bacterial pathogens involved in otitis media. Pneumococcal vaccination has been shown to reduce the rates of otitis media and tympanostomy tube insertion. ${ }^{37}$ However, these results were not as dramatic as expected, possibly due to infection by non-vaccine serotypes of pneumococci ("serotype replacement") or non-typeable $H$. influenzae (not covered by the $H$. influenzae

\section{Flowchart of management options for children with otitis media}

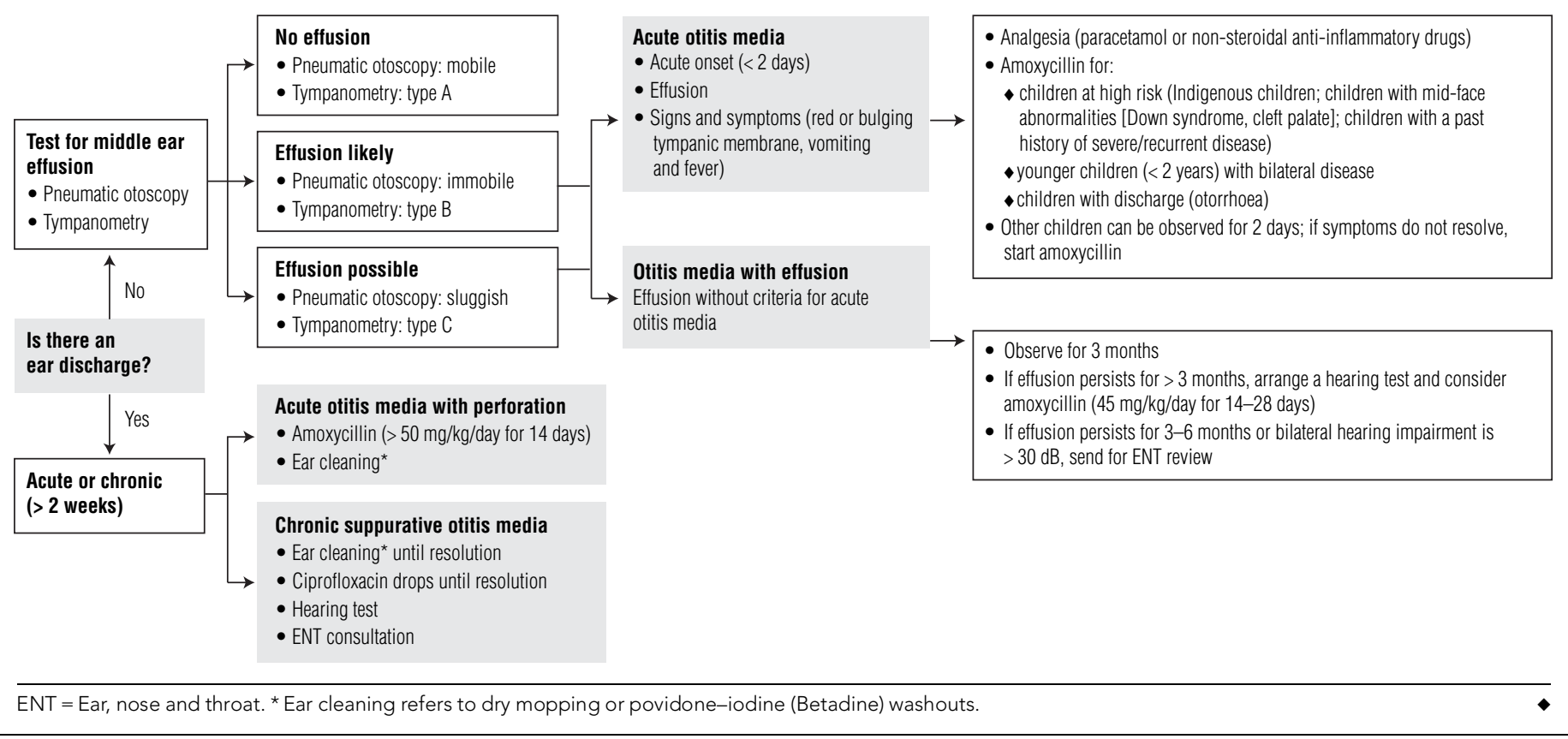




\section{SUPPLEMENT}

\section{Guidelines for referral to an ear, nose and throat specialist for otitis media ${ }^{40-42}$}

\section{Acute otitis media}

Elective referral

- Recurrent acute otitis media with three or more episodes in 6 months or four or more episodes in 12 months

Emergency referral

- Failure to respond to two courses of oral antibiotic therapy with persisting symptoms (eg, high fever or intractable pain)

- Complications of otitis media (eg, mastoiditis, facial nerve paralysis, meningitis, intracranial abscess or lateral sinus thrombosis)

\section{Otitis media with effusion}

Elective referral

- Middle ear effusion for 3 months or more with associated symptoms of hearing loss or speech and language delay

- Hearing loss $>30 \mathrm{~dB}$ with symptoms of speech delay, educational impairment or behavioural symptoms

- Significant retraction pocket in tympanic membrane

Chronic suppurative otitis media

Elective referral

- Persistent perforation of tympanic membrane, recurrent ear discharge, or retraction of tympanic membrane

- Suspected cholesteatoma

Emergency referral

- Development of complications of chronic suppurative otitis media or cholesteatoma (as for complications of acute otitis media)

\section{Children with conditions predisposing to otitis media}

Elective referral

- Down syndrome, cleft palate or craniofacial syndromes (eg, Apert syndrome and Crouzon syndrome). Patients with these conditions have high rates of otitis media and hearing loss, which may be missed to due to the complex nature of their problems

vaccination). A new second-generation pneumococcal conjugate vaccine, using the protein $\mathrm{D}$ of $\mathrm{H}$. influenzae as a protein carrier, is more encouraging for otitis media prevention. ${ }^{38}$ Influenza infection can precede AOM, but trials examining whether influenza vaccination decreases AOM rates have shown conflicting results. A Cochrane meta-analysis is currently underway. ${ }^{39}$

\section{Indications for specialist referral in otitis media}

The sequelae of otitis media include language and learning delay and, less commonly, mastoiditis, facial nerve paralysis, meningitis, intracranial abscess, and lateral sinus thrombosis. Any illness not progressing towards resolution as expected, even when the child is taking a course of antibiotics, should be a trigger for considering specialist referral (Box 4).

\section{Competing interests}

None identified.

\section{Author details}

Hasantha Gunasekera, DCH, FRACP, MIPH(Hons), General Paediatrician, ${ }^{1}$ and Clinical Lecturer ${ }^{2}$
Tony E O'Connor, AFRCSI, FRCS(ORL-HNS), Fellow in Paediatric Otolaryngology ${ }^{3}$

Shyan Vijayasekaran, MB BS, FRACS, Otolaryngologist, ${ }^{3}$ and Clinical Associate Professor ${ }^{4}$

Christopher B Del Mar, MD, FRACGP, Dean ${ }^{5}$

1 General Medicine, Children's Hospital at Westmead, Sydney, NSW.

2 School of Public Health, University of Sydney, Sydney, NSW.

3 Princess Margaret Hospital for Children, Perth, WA.

4 School of Surgery, University of Western Australia, Perth, WA.

5 Faculty of Health Sciences and Medicine, Bond University, Gold

Coast, QLD.

Correspondence: hasanthg@chw.edu.au

\section{References}

1 Leach AJ, Boswell JB, Asche V, et al. Bacterial colonization of the nasopharynx predicts very early onset and persistence of otitis media in Australian Aboriginal infants. Pediatr Infect Dis J 1994; 13: 239-247.

2 Morris PS. A systematic review of clinical research addressing the prevalence, aetiology, diagnosis, prognosis and therapy of otitis media in Australian Aboriginal children. J Paediatr Child Health 1998; 34: 487-497.

3 Nyquist A-C, Gonzales R, Steiner JF, Sande MA. Antibiotic prescribing for children with colds, upper respiratory tract infections, and bronchitis. JAMA 1998; 279: 875-877.

4 Froom J, Culpepper L, Green LA, et al. A cross-national study of acute otitis media: risk factors, severity, and treatment at initial visit. Report from the international primary care network (IPCN) and the ambulatory sentinel practice network (ASPN). J Am Board Fam Pract 2001; 14: 406417.

5 Davidson J, Hyde ML, Alberti PW. Epidemiologic patterns in childhood hearing loss: a review. Int J Pediatr Otorhinolaryngol 1989; 17: 239-266.

6 Roberts JE, Rosenfeld RM, Zeisel SA. Otitis media and speech and language: a meta-analysis of prospective studies. Pediatrics 2004; 113: e238-e248.

7 Morris $P$, Ballinger D, Leach A, et al. Recommendations for clinical care guidelines on the management of otitis media (middle ear infection) in Aboriginal and Torres Strait Islander populations. Canberra: Office for Aboriginal and Torres Strait Islander Health, Commonwealth Department of Health and Aged Care, 2001.

8 Antibiotic Expert Group. Therapeutic guidelines: antibiotic. Version 13. Melbourne: Therapeutic Guidelines Limited, 2006.

9 American Academy of Pediatrics Subcommittee on Management of Acute Otitis Media. Diagnosis and management of acute otitis media. Pediatrics 2004; 113: 1451-1465.

10 Heikkinen T, Thint $M$, Chonmaitree T. Prevalence of various respiratory viruses in the middle ear during acute otitis media. N Engl J Med 1999; 340: 260-264.

11 Sanders S, Glasziou PP, Del Mar C, Rovers M. Antibiotics for acute otitis media in children. Cochrane Database Syst Rev 2009. In press.

12 Rovers MM, Glasziou P, Appelman CL, et al. Antibiotics for acute otitis media: a meta-analysis with individual patient data. Lancet 2006; 368: 1429-1435.

13 Ashworth M, Latinovic R, Charlton J, et al. Why has antibiotic prescribing for respiratory illness declined in primary care? A longitudinal study using the General Practice Research Database. J Public Health (Oxf) 2004; 26: 268-274.

14 Kim SY, Chang YJ, Cho HM, et al. Non-steroidal anti-inflammatory drugs for the common cold. Cochrane Database Syst Rev 2009; (3): CD006362.

15 Meremikwu M, Oyo-lta A. Paracetamol for treating fever in children. Cochrane Database Syst Rev 2002; (2): CD003676.

16 Hayward G, Thompson M, Heneghan C, et al. Corticosteroids for pain relief in sore throat: systematic review and meta-analysis. BMJ 2009; 339: b2976.

17 Zalmanovici A, Yaphe J. Steroids for acute sinusitis. Cochrane Database Syst Rev 2007; (2): CD005149.

18 Thomas M, Del Mar C, Glasziou P. How effective are treatments other than antibiotics for acute sore throat? Br J Gen Pract 2000; 50: 817-820.

19 Foxlee R, Johansson A, Wejfalk J, et al. Topical analgesia for acute otitis media. Cochrane Database Syst Rev 2006; (3): CD005657.

20 Hildebrandt G, Lee IK. Xylitol containing oral products for preventing dental caries [protocol]. Cochrane Database Syst Rev 2004; (1): CD004620. 


\section{OTITIS MEDIA 2009: AN UPDATE}

21 Uhari M, Kontiokari T, Koskela M, et al. Xylitol chewing gum in prevention of acute otitis media: double blind randomised trial. BMJ 1996; 313: 1180-1184.

22 Bluestone CD, Klein JO. Otitis media and eustachian tube dysfunction. In: Bluestone CD, Stool SE, Alper CM, et al, editors. Pediatric otolaryngology. 4th ed. New York: Saunders, 2003: 474-685.

23 McDonald S, Langton Hewer CD, Nunez DA. Grommets (ventilation tubes) for recurrent acute otitis media in children. Cochrane Database Syst Rev 2008; (4): CD004741.

24 Cantekin El, McGuire TW. Antibiotics are not effective for otitis media with effusion: reanalysis of meta-analyses. Otorhinolaryngol Nova 1998; 8: 214-222.

25 American Academy of Pediatrics. Clinical practice guideline: otitis media with effusion. Pediatrics 2004; 113: 1412-1429.

26 Thomas CL, Simpson S, Butler C, van der Voort J. Oral or topical nasal steroids for hearing loss associated with otitis media with effusion in children. Cochrane Database Syst Rev 2006; (3): CD001935.

27 Simpson S, Thomas CL, van der Linden M, et al. Identification of children in the first four years of life for early treatment for otitis media with effusion. Cochrane Database Syst Rev 2007; (1): CD004163.

28 Williams RL, Chalmers TC, Stange KC, et al. Use of antibiotics in preventing recurrent acute otitis media and in treating otitis media with effusion. A meta-analytic attempt to resolve the brouhaha. JAMA 1993; 270: 1344-1351.

29 Rosenfeld RM, Post JC. Meta-analysis of antibiotics for the treatment of otitis media with effusion. Otolaryngol Head Neck Surg 1992; 106: $378-$ 386.

30 Perera R, Haynes J, Glasziou PP, Heneghan CJ. Autoinflation for hearing loss associated with otitis media with effusion. Cochrane Database Syst Rev 2006; (4): CD006285.

31 Lous J, Burton MJ, Felding J, et al. Grommets (ventilation tubes) for hearing loss associated with otitis media with effusion in children. Cochrane Database Syst Rev 2005; (1): CD001801.

32 Paradise JL, Feldman HM, Campbell TF, et al. Tympanostomy tubes and developmental outcomes at 9 to 11 years of age. N Engl J Med 2007; 356: 248-261.
33 Chow Y, Wabnitz DA, Ling J. Quality of life outcomes after ventilating tube insertion for otitis media in an Australian population. Int J Pediatr Otorhinolaryngol 2007; 71: 1543-1547.

34 Rosenfeld RM, Bhaya MH, Bower CM, et al. Impact of tympanostomy tubes on child quality of life. Arch Otolaryngol Head Neck Surg 2000; 126: 585-592.

35 Macfadyen CA, Acuin JM, Gamble CL. Systemic antibiotics versus topical treatments for chronically discharging ears with underlying eardrum perforations. Cochrane Database Syst Rev 2006; (1): CD005608.

36 van der Veen EL, Rovers MM, Albers FWJ, et al. Effectiveness of trimethoprim/sulfamethoxazole for children with chronic active otitis media: a randomized, placebo-controlled trial. Pediatrics 2007; 119: 897904.

37 Palmu A, Jokinen J, Kilpi T; Finnish Otitis Media Study Group. Impact of different case definitions for acute otitis media on the efficacy estimates of a pneumococcal conjugate vaccine. Vaccine 2008; 26: 2466-2470.

38 Prymula R, Peeters P, Chrobok V, et al. Pneumococcal capsular polysaccharides conjugated to protein $D$ for prevention of acute otitis media caused by both Streptococcus pneumoniae and non-typable Haemophilus influenzae: a randomised double-blind efficacy study. Lancet 2006; 367: 740-748.

39 Kay ES, Ng K, Salmon A, Del Mar C. Influenza vaccine for preventing acute otitis media in infants and children. Cochrane Database Syst Rev 2005; (3): CD005438.

40 American Academy of Otolaryngology, Head and Neck Surgery. 2000 Clinical indicators compendium. Alexandria, Va: AAOHNS, 2000: 10, 15 16.

41 The Otitis Media Guideline Panel. Managing otitis media with effusion in young children. American Academy of Pediatrics. Pediatrics 1994; 94: 766-773.

42 American Academy of Otolaryngology, Head and Neck Surgery. Ear problems in childhood. Revised Referral Guideline Kit. Alexandria, Va: AAOHNS, 2000.

(Received 26 Apr 2009, accepted 24 Aug 2009)

$\square$ 